\title{
On Perfume Advertisement in Film Art during the Digital Age
}

\author{
Rui Kong \\ Tianjin University of Commerce \\ Tianjin, China \\ PhD Program Class of Creative Industry \\ Shih Chien University \\ Taipei, Taiwan
}

\begin{abstract}
With the development of the digital age, Advertisement from static to dynamic, from dominant to recessive, film as an effective means of advertising communication, it has its own unique artistry and aesthetics. Embed perfume advertisement into the film's plot, combine the visual experience, smell experience the emotional experience together, to achieve the communication effects silently.
\end{abstract}

Keywords—digital age; perfume advertisement; film art

\section{INTRODUCTION}

When standing in the aroma with full bloom of flowers, the human body will produce pleasant sensation of aroma and form a visual imagination. Perfume odor can bring a section of memory which left people with the imagination space. The emergence of perfume at first is its functional demands, that their olfactory senses evoke "sexual attraction" or "sexual pleasant", and advertisement use public communication media through visual senses - image and name to guide consumers to meet their demands for self charming image, whether the product packaging (perfume bottle), or the use of the public communication media (perfume advertisement), perfume has became a consumption culture between popularity and the world. Impact on the society is that the perfume industry has its important role in social gender, character shaping, each kind of perfume will form a homogeneous social group in society. Almost when film appears, the major business companies always trying to embed their products into the films, and in the meanwhile theses business companies also became film's most important strategic partner. This article attempts to reflect cultural production and consumption spread in contemporary digital age through the application of perfume advertisements in films.

\section{THE HistORY ORIGIN OF PERFUME}

The origin of perfume is from the Latin Per fumes, literally translation is "through the smoke", the source of fragrance is incense, the origin of Fragrance is from Latin Fragro, and literally translation is "smell". Perfume materials derived from plants such as vetiver, sandalwood and so on; or derived from animals such as musk, castoreum, ambergris and so on. Human use spices for a long time, it can dated back to 13,000 years civilization of Shumo in ancient Mesopotamian, at that time people have started burning vegetation with spice ingredient for ceremonies and continually been used in rituals. Kingdom Ur burned myrrh (a kind of tree secretions) because they believe it will make the gods joy. India's oldest religious literature - "Vedas" records that in 10,000 years AD, people smeared oil made by spices all over their bodies in religious ceremonies or celebrations. In Egyptian tomb of Pharaoh, spices have been found in $3200 \mathrm{BC}$, and in Egyptian hieroglyphics, it was described that people at that time were commonly use fragrance in their lives and ritual activities. Imhotep,the Prime Minister of Djoser Dynasty want to please the supreme Amon-Ra God, he burned resin in the morning, burned myrrh at noon, burned kyphi in the evening (kyphi, essential oil which be loved by ancient Egyptian, it has hypnosis function). In $700 \mathrm{BC}$, there were hundreds of spice shops in ancient Greek city, herb plants trading has been peaked. In $100 \mathrm{BC}$, the Romans used spices for aphrodisiac, which called (Fire of Love). Romans use the spices three times a day, so they imported more than 2,800 tons of spices and 500 tons myrrh every year. Early 9th century during ancient Greek and Roman's banquets, the pigeons and other birds were soaked in precious perfume, and let the pigeons and birds shuttled back and forth within the guests, so the whole room will in aroma, it was considered the pioneer of the indoor aroma; until the Crusades in the 11th century opened the Oriental trade indirectly, the introduction of all kinds of spices and the extraction methods made the spices use change from rituals to the personal use; in 12th century, the Arabs found that dissolved essence with alcohol can slowly release the scent, some concentrated essence get better preservation due to alcohol ; until the 15th century, people already knew how to produce different application products with different spice ingredients and different alcohol concentration; to the 17th century, French perfume 's frame was growing. World famous French perfume company Houhigant and Gnerlain have been established, France has became the biggest perfume country in the world. In 1939, Swiss chemist Ruzicka studied the musk and clarified musk's chemical structure - giant muscone, which brought him the Nobel Prize.Since then, perfume bid farewell to the original ecology, creating a synthetic perfume era. After World War I, women were more independent in society and the economy, with the enhancement of women's consumption capacity, the perfume industry has created an 
unprecedented economic effect of billions of dollars. Since the 1980s, the perfume design and name design seemed to rise to exploring relative life philosophy. American Apparel master Calvin Klein released 3-steps perfume: Obsession, Eternity and Escape. It seems to tell the story of his personal perception of life with the fragrant smell, from indulging to great awakening until the eternal nirvana. In 1985 Aster Lauder released Beautiful, and pointed out the perfume selection should has personality, the application to wear perfume is to share their personal feelings and charm with the people around. Three years later, Aster Lauder launched Knowing, the strong fragrance made people can not ignore the presence of the user. For people's understanding and judgment about the perfume, except directly choose from shopping malls, knowing from the film plot is one of the ways which is first familiar with and then love and accept the perfume.

\section{ThE IMPLANT METHOD OF PERfume AdVERTISEMENT IN THE FILM ART}

Advertising implants are the direction of effort for all the business companies almost started from the beginning of the film appeared, no matter it is perfume or other forms of advertising. As early as the film "wing"won the first Academy Award for Best Picture in 1927, there was advertising implant, and after that almost every commercial film has placed advertising, and some implant even created a legendary commodity.

\section{A. Plot Implantation}

The film "Perfume" (English: Perfume: The Story of a Murderer; German: Das Parfüm-Die Geschichte eines Mörders) used plot implantation for perfume communication and got great success. It was a German film in 2006 which directed by Tom Tykwer. The film script was based on Suskind's novel "Perfume,"it described the genius Grenouille who did not contact with humans but with abnormal sense of smell sensitive to pursue the world's most perfect scent and finally kill people for that.

The film directly advocated the perfume charm which has come to the extent of metamorphosis, the man was willing to kill people in order to create the perfume which can charm all human being, at the last minute, he released the perfume and it made people all go crazy. Leaving aside the social significance of the film in the metaphor of film symbol, we only focus on cultural promotion of perfume, it made the audience deeply remember the perfume.

Also a well known film "Scent of a Woman", Al Pacino created a misanthropic with mean language blind old man, his wild laughter, unique military manner and his desolate and crafty eyes firmly attracted the attention of the audience, he got the best actor of the year with that film and also make "Scent of a Woman" this film which was taken in 1992 still exudes the charm of immortality. In the film, Lieutenant Colonel though blind, but he had a very keen sense of smell. When he took the the wine handed by stewardess on the plane, he was able to accurately call out her name "Daphne." Colonel explained that he smelled her perfume, Floris perfume from the old perfume shop of United Kingdom.
Floris (Chinese name: Floris) Founder: Juan Floris. So far it has been 283 years since established in 1730. Floris is British Royal Royal supplies which is praised by members of the royal family and many celebrities. Although it does not like gorgeous and strong French perfume, not like the United States perfume with full of energy, but as the as a traditional British perfume, Floris's strict and restrained style has left an elegant lady impression which is the best proof of its elegant,so it has been praised by many royalty and celebrities. In the film, the stewardess had eastern accent, and her name Daphne was just the most common name in eastern conservative families.

In the end of the film, Colonel has met the flavor which he loved the most and always look for on the female teacher who appreciate his generous speech, the flavor is perfume "Fleurs De Rocaille" from Caron .Caron is a French salon brand, luxurious and elegant, it was called the" crystal fountain ". "Fleurs De Rocaille" is a flower with noble and generous aroma and bloom in the adversity of break stones; it symbolizes the uncompromising chivalry. The gentle emotion of the whole story connected by the perfume from the beginning to the end.

\section{B. Hidden Implantation}

In the famous film "The Silence of the Lambs", Dr. Hannibal was a monster, he was ruthless, addicted to eat human flesh but also he was a gentleman with good manners and a very keen sense of smell. When he first saw Clarice, Dr. Hannibal was laughing at her rustic southern accent, he smelled the perfume Clarice used was "L'air du Temps"by Nina Ricci. "L'air du Temps" was a very classic French perfume which produced in 1948 known as its elegant. Aroma like wind flies through a cloud calm and quiet, elegant aroma did not match with Clarice's dress in the film, perfume was her self-comforting and salvation rather than a decoration. Audience's attention was attracted by the plot, no one would think of "L'air du Temps" perfume advertising has quietly entered the viewer's heart, because the story ,the advertising was easy to be accept and recognized by the audience ,the advertising result are good and natural.

\section{Direct Implantation}

With the development of the film industry, as the most "money burn" business during creative industries, financing is the first step of a successful film. With advertisers join in and formed a win-win business cooperation mode,advertisement from implicit to explicit, so advertising direct implantation became very normal, and some advertising even will play a lot before the film play, this was generally exhibitors' behavior. The other is implant the advertising shot in the play directly, such as the director Michel Bay in the movie " the Island " placed CK perfume which was considered a humorous propaganda, because the actress of this film was Scarlett Johansson, since it is cloned people film, the director simply put CK perfume ad which Scarlett taken with directly into the movie! The perfume is the "eternal moment."

\section{Mutual Effects of Smelling and Vision}

Psychology study found that currently, on both sides of the nose express different modulation effects to the visual 
processing. Such unilateral optimization effect proves: the regulation of visual information from smelling occurred in the primary processing stage of the brain. So we can see that in our daily sensory experiences, along with the smelling experience it will affect the results of the visual senses. The filled fragrance will increase our degree of visual pleasure. In everyday life we see flowers and then we will think of the fragrance of flowers, beautiful and easy experience from visual to smelling. This is a true mutual effect, and perfume advertising implanted in films makes effectively expansion of the advertising propagation and also improves the economic efficiency of its sales.

Whether from feelings of smell, visual and psychological, perfume ads use film as the inner marketing media to achieve the purpose of effective advertising and marketing communication.

\section{CUltural InTEgRATION OF THE PERfume COMMERCIALS AND FILM VISUAL CULTURE}

Film as a popular art media form can make art style deep into the life, artistic plot and scenes both can produce star effect and be pursued and admired by the public in order to greatly increase economic efficiency. The perfume ads in films appropriately and smoothly increase the unlimited imagination of viewer's sense of smell and visual interaction, and after the film finished, they could buy a perfume personally and extend the fragrance from the film to their own lives, produced a wonderful experience. This is the mutual benefit of cultural industries and commodities.

Film culture products not only are the product created by individual writers and artists, but rather motivate the next round of new industrial production process and the results. From perfume advertising creative planning, financing, production and distribution to actual consumption, cultural products have entered the market as mass-produced industrial products. Therefore, it must follow the commercialization rules of the market economy, and pursuit its commercial value as the goal. Perfume ads appear in the film allows the audience to accept it more close to nature, based on the story can give perfume a rich background tone, which greatly increases the audience's desire to purchase, to achieve a perfect binding between commercial value and artistic value of the film.

Modern science and technology provides the technical means for the public cultural goods, it introduces digital technology in manufacturing production, update the equipment, so that product quality of popular culture could follow international standards, in particular has been greatly improved in the development of the film industry. Social and industrialization operation mode of Mass culture has formed competitive enterprises in a market economy. Combination of advertising and mass culture, especially combined application of perfume ads in film art, formed a win-win operation mode which greatly improved the economic and artistic value.

\section{CONCLUSION}

This article starts from the perfume origins, to the formation process and the prevailing of perfume culture, and then it became the main consumption culture which has enormous economic value. Since the audience has natural resistance psychology for advertisements, so perfume advertisement through film as the communication media, to implant them into the film plots and combines the visual experience with olfactory experience and emotional experience in order to reach the communication effects smoothly. Film's hidden advertising jump out of the traditional advertising with straightforward appeal mode, sneak into the audience's perspective with hidden, active and moving forms, break through the psychological advertising barrier of the audience easily. Interaction of advertising and film achieves a win-win business mode.

\section{REFERENCES}

[1] Wang Chen "Who read westerly alone cool" Hunan Art Publishing Company 2011,P21 of the first edition

[2] Institute of Psychology, Chinese Academy of Sciences Network " Psychology study found that on both sides of the nose express different modulation effects to the visual processing" http://www.cas.cn/ky

[3] Li Juan, Qi Hao Technology Guide "Discussion about the application of hidden advertising in films"

[4] Wang Rong, Qin Suiming "application and development of art communication in commercial advertising " 2004.

[5] Liu Xiujuan, Lin Mingkuan translation of "gender relations: gender stereotype and character."Taipei, Yang Zhi culture 2010.9

[6] Huang Heshui “ Advertising psychology" [M] Beijing: Higher Education Press, 2005.06

[7] Qi Yumin, Su Yang, Li Qing “Advertising aesthetic: Principles and Cases" [M] Beijing: China Renmin University Press 2009.01 